\title{
The Influence of Hydrothermal Duration on Structures and Optical Properties of $\mathrm{ZnO}$ Nanoparticles
}

\author{
Akhiruddin ", Sugianto, Irmansyah \\ Department of Physics, Bogor Agricultural University, Darmaga, Bogor, Indonesia \\ *Corresponding author: akhiruddin@ipb.ac.id
}

Received August 21, 2014; Revised December 15, 2014; Accepted December 31, 2014

\begin{abstract}
ZnO}$ nanoparticles were synthesized by hydrothermal method using ethylene glycol as a stabilizer and as well as a template. This study was aimed to examine the influence of hydrothermal duration ( 3,6 , and 12 hours) on the structures and optical properties of $\mathrm{ZnO}$ nanoparticles. X-ray diffraction results show that all peaks appear in the diffraction pattern indicate the hexagonal wurtzite structure of $\mathrm{ZnO}$. The lattice parameters found just slightly varied with addition of hydrothermal duration. It is found that the particles size decreases whereas the average crystals size increase with hydrothermal duration. The average crystal size found increase with addition of hydrothermal duration. On the other hand, the particle grains were spread evenly distributed with decreasing size with hydrothermal duration increase, as indicated in the SEM images. Optical properties were investigated based on the optical transmission of the $\mathrm{ZnO}$ films. It is known that the films strongly absorb the visible region, whereas the absorption edge in the UV region. Bandgap energy of the films found increase with hydrothermal duration, that were $3.18 \mathrm{eV}, 3.21 \mathrm{eV}$ and $3.24 \mathrm{eV}$ for 3 hours, 6 hours and 12 hours, respectively.
\end{abstract}

Keywords: ZnO nanoparticles, hydrothermal process, duration effect, structues, optical properties

Cite This Article: Akhiruddin, Sugianto, and Irmansyah, "The Influence of Hydrothermal Duration on Structures and Optical Properties of ZnO Nanoparticles." Journal of Materials Physics and Chemistry, vol. 2, no. 2 (2014): 34-37. doi: 10.12691/jmpc-2-2-4.

\section{Introduction}

$\mathrm{ZnO}$ is well known as n-type semiconductor materials which have band gap energy about $3.37 \mathrm{eV}$ at room temperature and $3.34 \mathrm{eV}$ at low temperatures [1]. $\mathrm{ZnO}$ has a hexagonal (wurtzite) crystal structure with lattice parameter $\mathrm{a}=3.249 \AA$ and $\mathrm{c}=5.206 \AA$ [2]. Many applications have been known for $\mathrm{ZnO}$ semiconductor including in dye sensitized solar cells $[3,4,5]$, gas sensors [6], UV light sensors [7], photocatalysts [8], thin film transistors (TFTs) [9], transparent conducting layers [10], light emitting devices [11], and as blocking layer in flexible organic solar cell [12].

Several methods have been established to grow the $\mathrm{ZnO}$ crystal such as sol-gel [13,14], hydrothermal [15,16], spray pyrolysis [17], sonochemistry [18], electrochemical growth [19], electrophoretic [20], and chemical bath deposition (CBD) [21,22]. Hydrothermally processing is one of the more effective and efficient method because the temperature and pressure can be controlled which greatly effects the results. Several researches have studied any factors in the hydrothermal synthesis of $\mathrm{ZnO}$ nanoparticles including variation of temperature and pressure in the reactor $[14,15]$. But, there were no more researches that have study the duration effect in the hydrothermal processing of $\mathrm{ZnO}$ nanoparticles.

In this research we studied the influence of duration of hydrothermal processing on the properties of $\mathrm{ZnO}$ nanoparticles. This study will investigate the structure, morphology and optical properties of the $\mathrm{ZnO}$ nanoparticle in relation with duration of hydrothermally process.

\section{Experimental}

Any chemicals used to synthesize the $\mathrm{ZnO}$ nanoparticles were analytical grade. Firstly, 8.75 grams of zinc acetate dehydrate was dissolved into $28 \mathrm{ml}$ of ethanol and $12 \mathrm{ml}$ ethylene glycol. Then the solutions added to an autoclave of hydrothermal reactor. Temperature of the reactor fixed at $150^{\circ} \mathrm{C}$, while stirred at $400 \mathrm{rpm}$ for different duration that are 3 hours, 6 hours and 12 hours. The sediment derived from hydrothermal process was washed with ethanol three times and dried on the hotplate at $100^{\circ} \mathrm{C}$ until it dry and then calcination at $300^{\circ} \mathrm{C}$ for one hour. Afterward, the samples were characterized using $\mathrm{X}$ ray diffraction (XRD) to determine the structure of crystal and scanning electron microscope (SEM) to determine the morphology of the samples.

To study the optical properties of $\mathrm{ZnO}$ nanoparticles, the $\mathrm{ZnO}$ powder samples were formed into film form onto the glass substrate. $\mathrm{ZnO}$ films were coated on the ITO glass by casting method. Before that, $\mathrm{ZnO}$ powder was dispersed into ethylene glycol at $5 \mathrm{wt} \%$ concentration and ethanol [23]. The films were coated on the glass substrate with $1.5 \mathrm{~cm} \times 1 \mathrm{~cm}$ area. Optical properties of $\mathrm{ZnO}$ film were measured using UV-Vis spectrophotometer (Ocean Optics), from which the bandgap energy will be determined. 


\section{Results and Discussion}

\subsection{XRD Analysis}

Figure 1 shows the diffraction pattern of $\mathrm{ZnO}$ nanoparticles derived by hydrothermal process with different duration. Any samples have been thermally treated with a same temperature $\left(300^{\circ} \mathrm{C}\right)$. There are no more significantly difference of the pattern resulted by any samples with variation of hydrothermal duration. Based on the diffraction patterns it can conclude that the $\mathrm{ZnO}$ crystal well growth perfectly. All of the $\mathrm{ZnO}$ peaks appears in the pattern indicate the $\mathrm{ZnO}$ crystal have growth well with a hexagonal (wurtzite) structure, as three higher peaks at about $2 \theta=36^{\circ}(101)$, and $\left.32^{\circ} 100\right)$, $34^{\circ}(002)$, respectively [24].

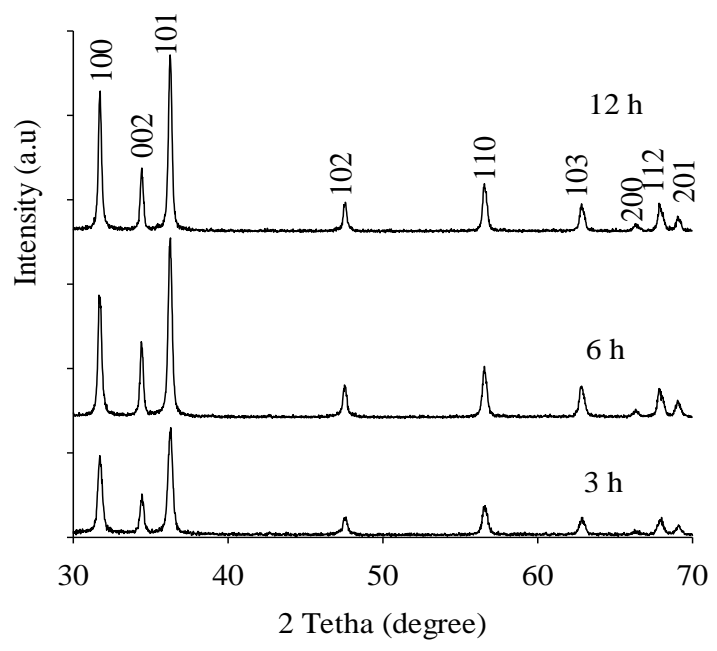

Figure 1. Diffraction patterns of $\mathrm{ZnO}$ nanoparticle with different hydrothermal duration, $3 \mathrm{~h}, 6 \mathrm{~h}$ and $12 \mathrm{~h}$

Using Cohen method, it can be calculated the lattice parameters of hexagonal $\mathrm{ZnO}$ crystal [23]. The lattice parameters ( $a$ and $c$ ) were found just slightly different for the samples with different hydrothermal duration. For 3 hours of hydrothermal duration found the parameter $a=$ $3.25 \AA$ and $c=5.21 \AA$. For 6 hours duration have the parameter $\mathrm{a}=3.26 \AA$ and $\mathrm{c}=5.22 \AA$, whereas for 12 hours duration have the parameter $\mathrm{a}=3.26 \AA$ and $\mathrm{c}=5.22 \AA$. The parameters slightly increase with hydrothermal duration increase. These calculation values are agreement with the previous research, such as the results obtained by Hamedani, et.al [25].

The average crystal size (ACS) of $\mathrm{ZnO}$ was calculated using a well-known Scherrer's formula

$$
\sigma=\frac{k \lambda}{\beta \cos \theta}
$$

$\sigma$ is the average of crystal size, $k$ is a constant $(0.9), \lambda$ is the wavelength of X-ray source (1.54059 $\AA$ ), $\beta$ is the fullwidth half maximum (FWHM), and $\theta$ is the angle of diffraction. The calculation results found the average crystal size of $\mathrm{ZnO}$ nanoparticle increases with hydrothermal duration increase (Figure 3). For 3 hours hydrothermal duration, it found the crystal size of 44.32 $\mathrm{nm}$, and increase to $50.65 \mathrm{~nm}$ for 6 hours and $54.37 \mathrm{~nm}$ for 12 hours of hydrothermal duration. There was no more previous information about reduction of crystal size with hydrothermal duration increase.

\subsection{Morphology}

The surface morphology of $\mathrm{ZnO}$ was observed by scanning electron microscopy (SEM). Figure 2 ( $a, b$ and $c$ ) shows the SEM images of three samples prepared with three different hydrothermal duration, that are 3, 6, and 12 hours, respectively. The images present the clearly surface morphology of the samples. Grains boundary of the particles clearly seems on the morphology images, so that the particles size can be measured using CorelDRAW software.

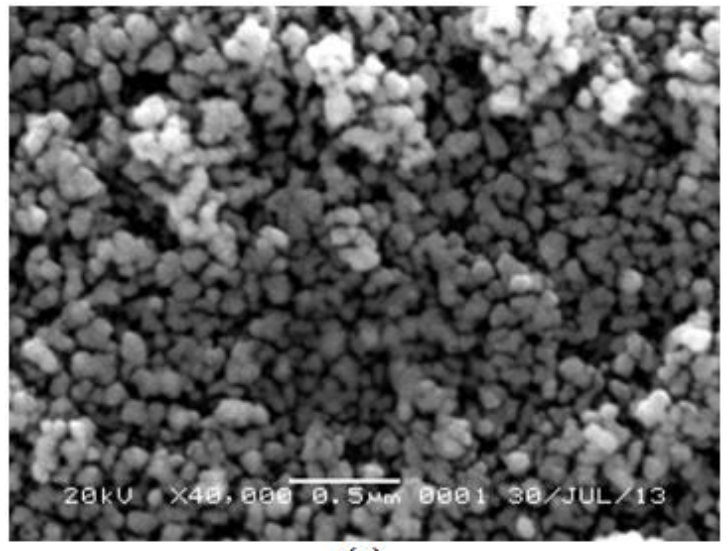

(a)

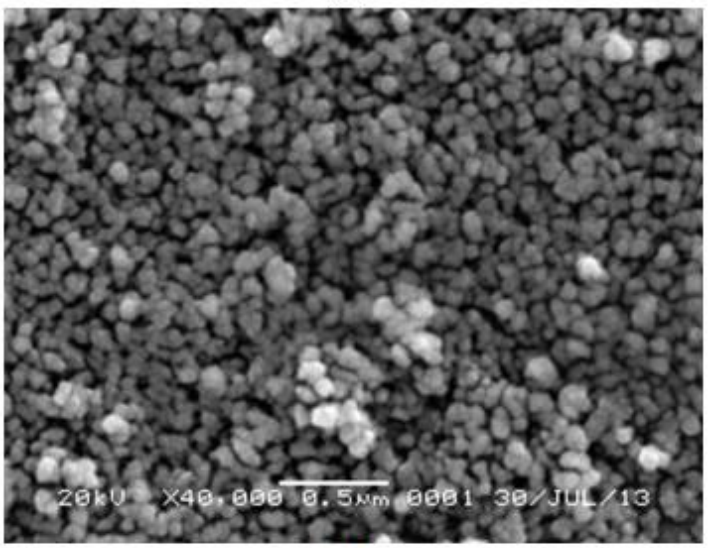

(b)

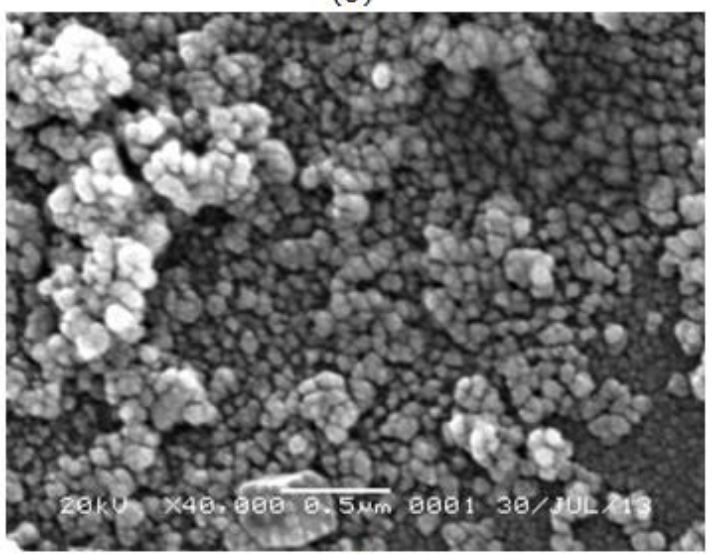

(c)

Figure 2. SEM photograph of $\mathrm{ZnO}$ film for (a) 3 hours, (b) 6 hours, and (c) 12 hours hydrothermal duration

In contrast to the crystal size, the grain size of particle was found decreased with time duration increase of hydrothermal process, as shown in the curves at Figure 3. It found the particle size for 3 hours of hydrothermal duration was $249 \mathrm{~nm}$, increased to $147 \mathrm{~nm}$ and $107 \mathrm{~nm}$ for 6 hours and 12 hours of duration, respectively. This result 
is consistent to facts that reduction of particles size in line with the lattice parameter increase [26].

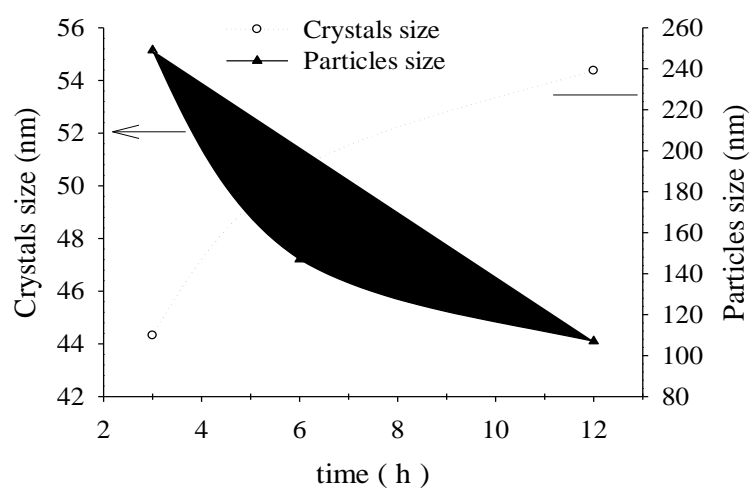

Figure 3. Effect of hydrothermal duration to particle and crystal size of $\mathrm{ZnO}$ nanoparticles

Regarding the facts, it found that addition of hydrothermal duration caused the particle size of $\mathrm{ZnO}$ nanoparticle decrease, otherwise the crystal size increase. In the other research, it found that the particle size will decrease with temperature and concentration increase [25].

\subsection{Optical Properties}

The optical properties of $\mathrm{ZnO}$ semiconductor was investigated based on observation of optical transmissions through the semiconductor films by using UV-Vis spectrophotometer. Figure 4 shows the optical transmission of $\mathrm{ZnO}$ films with variation of hydrothermal duration. The transmittance spectra show that the $\mathrm{ZnO}$ films strongly absorb the UV region of electromagnetic spectrum, with the absorption edge at around the $400 \mathrm{~nm}$. It found that the spectra were shifted to a longer wavelength with hydrothermal duration increase that means their optical properties have change. The maximum of absorption also shifts to longer wavelength, that about $306 \mathrm{~nm}, 467 \mathrm{~nm}$ and $264 \mathrm{~nm}$ for 3 hours, 6 hours and 12 hours duration of hydrothermal reaction.

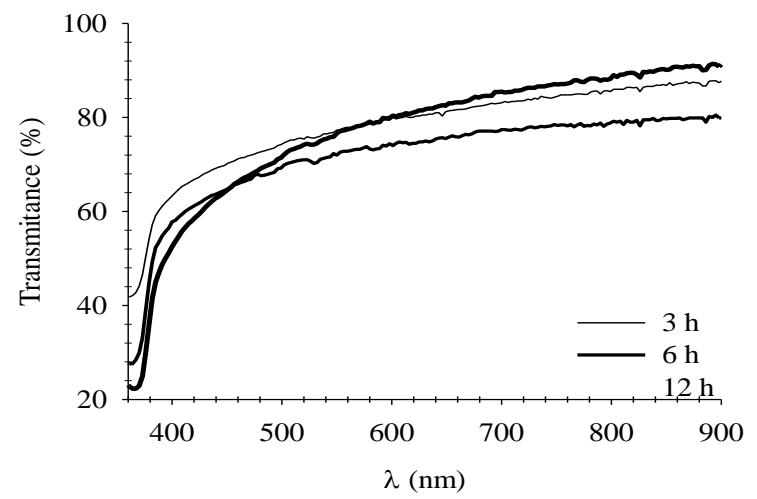

Figure 4. Optical transmission of $\mathrm{ZnO}$ films with different hydrothermal duration

The shift of the absorption edge to higher wavelength was caused by the reduction of the transition distance between energy levels usually called band gap energy. The results confirm that band gap energy will decrease as with increasingly particle size caused by the quantum size effect [26].

In order to determine the band gap energy of the films, the transmittance or absorbance spectra of the films were recorded. The absorption coefficient $(\alpha)$ was calculated from the transmittance or absorbance spectra using the formula

$$
\alpha(v)=2.303(\mathrm{~A} / \mathrm{d})
$$

where $\alpha$ is the absorbance coefficient, $d$ is the film thickness and $A$ is the optical absorbance. The thickness of the films was determined based on cross section image of the films by SEM.

The optical absorption edge was analyzed by the following equation to determine the band gap energy of the films [24],

$$
\alpha h v=A\left(h v-E_{g}\right)^{m}
$$

where $A$ is a constant, $m$ value was characterized by kind of transition, that values are $1 / 2$ for direct and 2 for indirect transition, respectively. It known that the $\mathrm{ZnO}$ is a direct transition semiconductor, so the $m$ value is $1 / 2$. Based on the above equation, it can be plotted a curve between $\alpha h v$ as vertical axis with photon energy $(h v)$ as horizontal axis, usually called Tauc plot from which the band gap energy $\left(E_{\mathrm{g}}\right)$ can be determined.

Figure 5 shows a Tauc plot for the three different $\mathrm{ZnO}$ nanoparticle films with variation of hydrothermal duration. The plots show the clearly transition region around $3,2 \mathrm{eV}$, that consistent with band gap energy of $\mathrm{ZnO}$ semiconductor. Regarding to the plot, it exactly found the band gap energy of $\mathrm{ZnO}$ films increase with addition of hydrothermal duration, i.e. $3.18 \mathrm{eV}, 3.21 \mathrm{eV}$ and $3.24 \mathrm{eV}$ for 3 hours, 6 hours and 12 hours of hydrothermal duration. In this case, the $\mathrm{ZnO}$ nanoparticle films is a directly transition semiconductor, as has been expressed by previous researchers $[17,22]$.

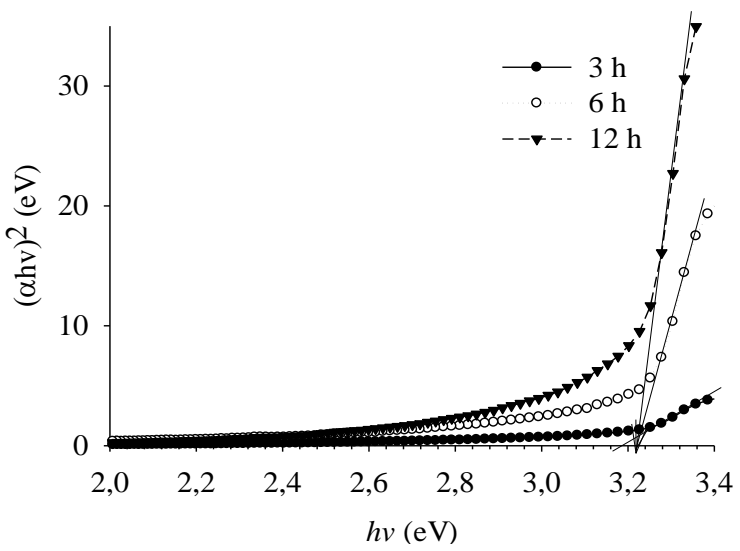

Figure 5. Touch plot $(\alpha \mathrm{hv})^{2}$ versus the energy of photons (hv)

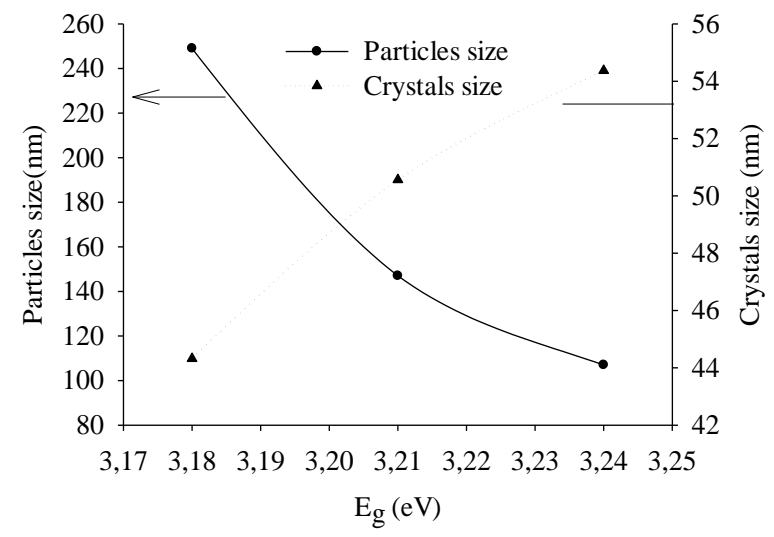

Figure 6. A shift Band gap energy versus partilces and crystals size 
According to the previous explanation that band gap energy shift was caused by difference of particles size. In the theory, decreasing particles size will increase the band gap energy of semiconductor materials. A change of band gap energy to crystals size and particles size can be seen in Figure 6. Based on this result, it found that duration of hydrothermal reaction caused the particles size decrease causing the band gap energy increase.

\section{Conclusions}

$\mathrm{ZnO}$ nanoparticles have been synthesized by hydrothermal method with variation of processing duration. The particle size of $\mathrm{ZnO}$ nanoparticles decrease, otherwise the crystal size increase with hydrothermal duration. On the other hand, optical band gap energy increase with hydrothermal duration caused by particles size decrease of $\mathrm{ZnO}$ nanoparticles as consequence of the quantum size effect.

\section{References}

[1] Takenaka, K., Okumura, Y. and Setsuhara, Y., "Low-Temperature Deposition of Zinc Oxide Film by Plasma-Assisted Mist Chemical Vapor Deposition,” Jpn. J. Appl. Phys., 51(8S1)).567-0047. August. 2012.

[2] Wang, Z.J. and Tanaka, I., "Conduction-Band Structures of Wurtzite ZnO Solid Solutions by First Principles Calculations," Mater. Transac., 50(5). 1067-1070. March 2009.

[3] Zhang, Q., Dandeneau, C.S., Zhou, X. and G. Cao, "ZnO Nanostructures for Dye-Sensitized Solar Cells," Adv. Mater., 21(41). 4087-4108. Nov. 2009

[4] Chou, T.P., Zhang, Q., Fryxell, G.E. and G. Cao, "Hierarchically Structured $\mathrm{ZnO}$ Film for Dye-Sensitized Solar Cells with Enhanced Energy Conversion Efficiency," Adv. Mater. 19(18). 2588-2582. Sept. 2007.

[5] J. Han, J., Fan, F., Xu, C., Lin, S., Wei, M., Duan, X. and Wang, Z.L., "ZnO nanotube-based dye-sensitized solar cell and its application in self-powered devices," Nanotechn. 21(40). 405203. Oct. 2010.

[6] Hung, Ng.L., Ahn, E., Jung, H., Kim, H. and D. Kim, "Synthesis and Gas Sensing Properties of $\mathrm{ZnO}$ Nanostructures," J. Kor. Phys. Soc. 57(6). 1784-1788. Dec. 2010.

[7] Gimenez, A.J., Yáñez-Limón, J.M. and Seminario, J.M., "ZnO-Paper Based Photoconductive UV Sensor," J. Phys. Chem. C. 115(1). 282-287. Jan. 2011.

[8] Lei, A., Qua, B., Zhou, W., Wang, Y., Zhang, Q. and Zou, B., "Facile synthesis and enhanced photocatalytic activity of hierarchical porous $\mathrm{ZnO}$ microspheres," Mater. Lett., 66. 72-75. Jan. 2012.

[9] Xiaming, Z., Huizhen, W., Shuangjiang, W., Yingying, Z., Chunfeng, C., Jianxiao, S., Zijian, Y., Xiaoyang, D. and Shurong, D., "Optical and electrical properties of $\mathrm{N}$-doped $\mathrm{ZnO}$ and fabrication of thin-film transistors," J. Semicond., 30(3). 033001-1 - 033001-4. March 2009.
[10] Keum, M-J., Cho, B-J., Choi, H-W., Parka, S-J. and K-H. Kim, "Preparation of $\mathrm{Al}$ doped $\mathrm{ZnO}$ thin films as a function of substrate temperature by a facing target sputtering system," J. Ceram. Process. Res. 8(1). 56-58. Jan. 2007.

[11] Jha, S.K., Kutsay, O., Bello, I. and Lee, S.T., " $\mathrm{ZnO}$ nanorod based low turn-on voltage LEDs with wide electroluminescence spectra," J. Luminesc. 133. 222-225. Jan. 2013.

[12] Lee, C.Y., Lin, M.Y., Wu, H.W., Wang, J.Y., Chou, Y., Su, W.F., Chen, Y.F. and Lin, C.F., "Flexible $\mathrm{ZnO}$ transparent thin-film transistors by a solution-based process at various solution concentrations," Semicond. Sci. Technol. 25(10), 105008. Oct. 2010.

[13] Karami, H. and Elham, F., "Synthesis and Characterization of $\mathrm{ZnO}$ Nanorods Based on a New Gel Pyrolysis Method," J. Nanomat., (10). 1155. 2011.

[14] Raoufi, D. and Raoufi, T., "The effect of heat treatment on the physical properties of sol-gel derived $\mathrm{ZnO}$ thin films," Appl. Surf. Sci., 255. 5812-5817. Jan. 2009.

[15] Aneesh, P.M., Vanaja, K.A. and Jayaraj,M.K., "Synthesis of ZnO nanoparticles by hydrothermal method", Proc. SPIE 6639, Nanophotonic Materials IV, 66390J. (September 17, 2007).

[16] Meen, T.H., Water, W., Chen, Y.S., Chen, W.R., Ji, L.W. and Huang, C.J., "Growth Of ZnO Nanorods by Hydrothermal Method Under Different Temperatures," [The research is supported by National Science Council], 150-028. 2007.

[17] Kumar, N.S., Bangera, K.V. and Shivakumar, G.K., "Effect of annealing on the properties of zinc oxide nanofiber thin films grown by spray pyrolysis technique," Appl. Nanosci., 4. 209-216. Jan. 2014.

[18] Kandjani, A.E., Tabriz, M.F. and Pourabbas, B., "Sonochemical synthesis of $\mathrm{ZnO}$ nanoparticles: The effect of temperature and sonication power," Mater. Res. Bull. 43(3). 645-654. March 2008

[19] Ko, Y.H., Kim, M.S. and Yu, J.S., "Structural and optical properties of $\mathrm{ZnO}$ nanorods by electrochemical growth using multi-walled carbon nanotube-composed seed layers," Nanoscale Res. Lett., 7(1). 13 (2012).

[20] Hara, Y., Brownson, J.R.S. and Anderson, M.A., "Fabrication of Thin-Films Composed of $\mathrm{ZnO}$ Nanorods Using Electrophoretic Deposition," Int. J. Appl. Ceram. Technol., 9 [1]. 115-123. Jan./Feb. 2012.

[21] Khallaf, H., Chai, G., Lupan, O., Heinrich, H., Park, S., Schulte, A.and Chow, L., "Investigation of chemical bath deposition of $\mathrm{ZnO}$ thin films using six different complexing agents," J. Phys. D: Appl. Phys. 42(13). 135304. July 2009.

[22] Shabannia, R. and Abu-Hassan, H., "Vertically aligned $\mathrm{ZnO}$ nanorods synthesized using chemical bath deposition method on seed-layer $\mathrm{ZnO} /$ polyethylene naphthalate (PEN) substrates," Mater. Lett. 90. 156-158. Jan. 2013.

[23] Ibrahem, M.A., Wei, H-Y., Tsai, M-H., Ho, K-C., Shyue, J-J. and Chu, C.W., Solution-processed zinc oxide nanoparticles as interlayer materials for inverted organic solar cells," Solar Energy Materials \& Solar Cells, 108. 156-163. Jan. 2013.

[24] Wu, Y.L., Tok, A.I.Y., Boey, F.Y.C., Zen, X.T.X. and Zhang, X.H., "Surface modification of $\mathrm{ZnO}$ nanocrystals," App. Surface Sci., 253(12). 5473-5479. April 2007.

[25] Hamedani, N.F. and Farzaneh, F.,"Synthesis of ZnO Nanocrystals with Hexagonal (Wurtzite) Structure in Water Using Microwave," J. Sci., 17(3). 231-234. 2006

[26] Xing, J.Y., Xi, Z.H., Xue, Q., Zhang, X.D. and J.H. Song, "Optical properties of the $\mathrm{ZnO}$ nanotubes synthesized via vapor phase growth,” Appl. Phys. Lett., 83(9). 1689-1691. Sep 2003. 